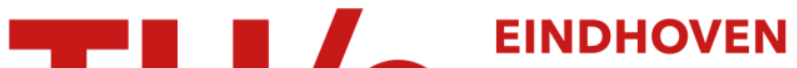 \\ UNIVERSITY OF \\ TECHNOLOGY
}

\section{Multimodel strong coupling of photonic crystal cavities of dissimilar size}

Citation for published version (APA):

Dundar, M. A., Voorbraak, J. A. M., Nötzel, R., Fiore, A., \& Heijden, van der, R. W. (2012). Multimodel strong coupling of photonic crystal cavities of dissimilar size. Applied Physics Letters, 100(8), 1-4. [081107]. https://doi.org/10.1063/1.3688301

DOI:

10.1063/1.3688301

Document status and date:

Published: 01/01/2012

\section{Document Version:}

Publisher's PDF, also known as Version of Record (includes final page, issue and volume numbers)

\section{Please check the document version of this publication:}

- A submitted manuscript is the version of the article upon submission and before peer-review. There can be important differences between the submitted version and the official published version of record. People interested in the research are advised to contact the author for the final version of the publication, or visit the $\mathrm{DOI}$ to the publisher's website.

- The final author version and the galley proof are versions of the publication after peer review.

- The final published version features the final layout of the paper including the volume, issue and page numbers.

Link to publication

\section{General rights}

Copyright and moral rights for the publications made accessible in the public portal are retained by the authors and/or other copyright owners and it is a condition of accessing publications that users recognise and abide by the legal requirements associated with these rights.

- Users may download and print one copy of any publication from the public portal for the purpose of private study or research.

- You may not further distribute the material or use it for any profit-making activity or commercial gain

- You may freely distribute the URL identifying the publication in the public portal.

If the publication is distributed under the terms of Article 25fa of the Dutch Copyright Act, indicated by the "Taverne" license above, please follow below link for the End User Agreement:

www.tue.nl/taverne

Take down policy

If you believe that this document breaches copyright please contact us at:

openaccess@tue.nl

providing details and we will investigate your claim. 


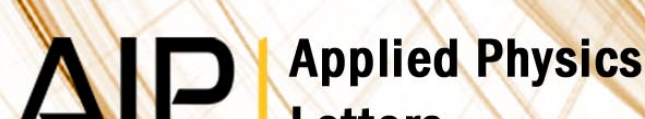 Letters}

Multimodal strong coupling of photonic crystal cavities of dissimilar size

Mehmet A. Dündar, Joost A. M. Voorbraak, Richard Nötzel, Andrea Fiore, and Rob W. van der Heijden

Citation: Appl. Phys. Lett. 100, 081107 (2012); doi: 10.1063/1.3688301

View online: http://dx.doi.org/10.1063/1.3688301

View Table of Contents: http://apl.aip.org/resource/1/APPLAB/v100/i8

Published by the American Institute of Physics.

\section{Related Articles}

High-Q aluminum nitride photonic crystal nanobeam cavities

Appl. Phys. Lett. 100, 091105 (2012)

Magnetophotonic crystal comprising electro-optical layer for controlling helicity of light J. Appl. Phys. 111, 07A913 (2012)

Highly modified spontaneous emissions in YVO4:Eu3+ inverse opal and refractive index sensing application Appl. Phys. Lett. 100, 081104 (2012)

High quality factor two dimensional GaN photonic crystal cavity membranes grown on silicon substrate Appl. Phys. Lett. 100, 071103 (2012)

Extraction of optical Bloch modes in a photonic-crystal waveguide

J. Appl. Phys. 111, 033108 (2012)

\section{Additional information on Appl. Phys. Lett.}

Journal Homepage: http://apl.aip.org/

Journal Information: http://apl.aip.org/about/about_the_journal

Top downloads: http://apl.aip.org/features/most_downloaded

Information for Authors: http://apl.aip.org/authors

\section{ADVERTISEMENT}

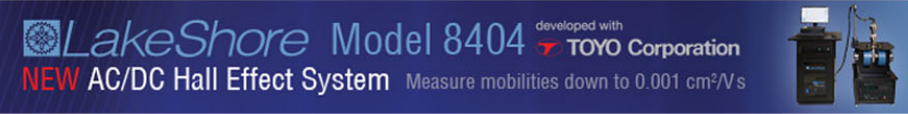




\title{
Multimodal strong coupling of photonic crystal cavities of dissimilar size
}

\author{
Mehmet A. Dündar, ${ }^{\text {a) }}$ Joost A. M. Voorbraak, Richard Nötzel, ${ }^{\text {b) }}$ Andrea Fiore, \\ and Rob W. van der Heijden ${ }^{\text {c) }}$ \\ Department of Applied Physics and COBRA Research Institute, Eindhoven University of Technology, \\ P.O. Box 513, NL-5600 MB Eindhoven, The Netherlands
}

(Received 2 October 2011; accepted 5 February 2012; published online 22 February 2012)

\begin{abstract}
A photonic crystal three missing holes nanocavity, having only a few modes, is coupled to a 60 missing holes long multimode cavity, both fabricated in the same InGaAsP membrane. The coupling was studied in detail by the photothermal tuning of the small cavity over about three free spectral ranges of the large cavity. Strong coupling effects, involving at least three large cavity modes simultaneously, were observed from level anticrossing data. The observations are excellently reproduced by a model of coupled Fabry Perot resonators. (c) 2012 American Institute of Physics. [http://dx.doi.org/10.1063/1.3688301]
\end{abstract}

Interacting optical resonators have been intensively studied both because of their fundamental interest and because of their applications. In recent years, much work has appeared on coupled photonic crystal $(\mathrm{PhC})$ cavities since they present the smallest possible dielectric optical resonators that can be made, imposed by the diffraction limit. They are expected to find application as building blocks of lasers ${ }^{1}$ or delay lines ${ }^{2-5}$ in future integrated photonic circuits or in on-chip quantum optical devices. ${ }^{6}$ The majority of these works deals with the coupling between identical cavities in two-dimensional arrays, ${ }^{1,7}$ line arrays, ${ }^{2,3,8-10}$ or in photonic molecules consisting of only two cavities. ${ }^{11-18}$ Coupling between non-identical cavities was already studied in very early work, albeit in poorly defined cavities. ${ }^{19}$ More recently, the coupling between different modes existent in identical cavities was reported. ${ }^{14}$ Also, an extended local defect has been described in terms of a coupled set of three or five small resonators. ${ }^{20}$ In the present paper we report the coupling between $\mathrm{PhC}$ cavities that differ by a factor of 20 in size. Unambiguous evidence for the coupling of a single mode from the small cavity with multiple closely spaced modes of the large cavity is obtained from level anticrossing behaviour when the small cavity frequency was tuned.

The cavities were made in a $220 \mathrm{~nm}$ thick InGaAsP membrane hexagonal photonic crystal with a layer of InAs Quantum Dots (QDs) in the center to generate photoluminescence (PL) near a wavelength of $1.5 \mu \mathrm{m}$ (see Fig. 1(a)). The small cavity, designated as $L 3$, consists of three missing air holes, with the end holes modified in size and/or position. The large cavity ("L60") consists of 60 missing air holes. The two cavities are separated by 2,3 , or 4 (rows of) holes, in the shoulder coupling configuration, where both cavities are oriented under $60^{\circ} .{ }^{21}$ There are $L 3$ cavities at each end of the $L 60$, but for the present work one can be ignored since it

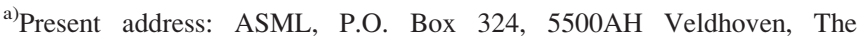
Netherlands.

${ }^{b}$ Present address: Institute for Systems based on Optoelectronics and Microtechnology (ISOM), ETSI Telecommunication, Technical University of Madrid, Ciudad Universitaria s/n, 28040 Madrid, Spain

${ }^{c)}$ Electronic mail: r.w.v.d.heijden@tue.nl.
}

is tuned out of resonance. Both cavities can be thought of as being derived from an infinitely long waveguide consisting of a one missing row of air holes, known as $W 1$ waveguide. The dispersion relations of the two lowest $W 1$ waveguide modes ("even" and "odd") are shown in Fig. 1(b).

The cavity spectra, both for the case of isolated and coupled cavities, were obtained from micro PL. A $660 \mathrm{~nm}$ excitation source is focused at the $L 3$ cavity by a microscope objective with numerical aperture 0.5 . The PL light is

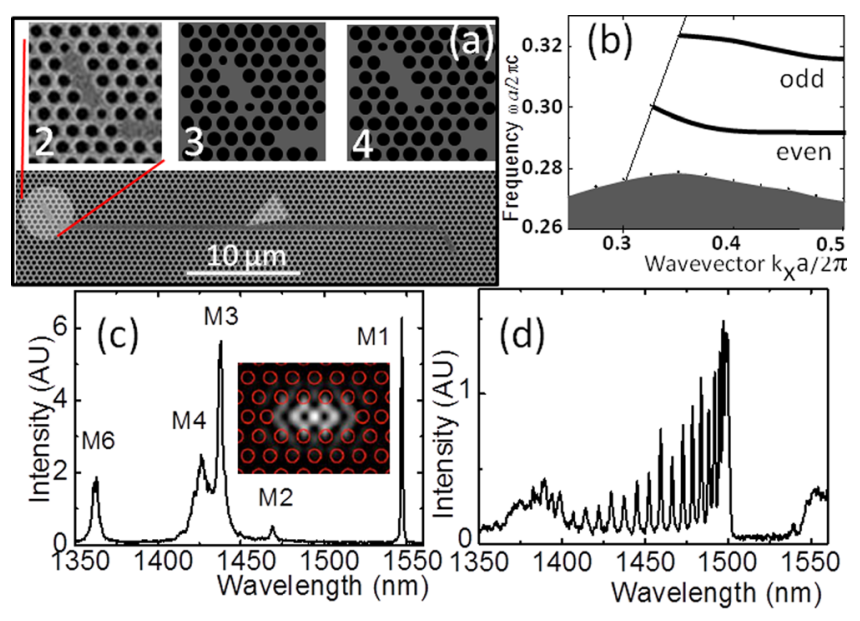

FIG. 1. (Color online) (a) Scanning electron microscope image of the coupled cavities device. The light-shaded areas designate the excitation spot (circle) and a position for the SNOM probe (triangle). Insets show an expanded view of $L 3$ with 2-hole barrier and sketches of 3- and 4-hole barriers. (b) Part of the band diagram of the photonic crystal with a one row of missing holes waveguide, showing the dispersion relation of the even and odd parity mode of the $W 1$ waveguide. Lattice constant $a=425 \mathrm{~nm}$; hole radius $r=0.3 a$; membrane thickness $t=220 \mathrm{~nm}$. (c) Photoluminescence (PL) spectrum of a typical (isolated) $L 3$ cavity ( $a=445 \mathrm{~nm} ; r / a \approx 0.3$ ) The endholes have a reduced radius $r^{\prime} \approx 0.22 a$, their positions are not shifted; the inset shows the intensity distribution of mode $M 1$ at midplane (Ref. 22). (d) PL spectrum of a typical (isolated) $L 60$ cavity $(a=425 \mathrm{~nm} ; r / a \approx 0.3)$. The structure near $1550 \mathrm{~nm}$ corresponds to the bulk PhC dielectric band edge. The cavities for (c) and (d) were separately fabricated on a different part of the same chip as the coupled cavities. For (c) the excitation and collection were both done with the microscope objective, focused on the $L 3$ cavity center. For (d), the excitation laser spot was focused by the objective near the end of the $L 60$ cavity, while the collection was done with the SNOM probe, positioned along the $L 60$ cavity, close ( $\sim$ few microns) to the excitation spot. 
collected either from the same location through the same objective or at a second independent location by the tip of a scanning nearfield optical microscope (SNOM). The PL from $L 3$ is always collected through the same objective as used for the excitation. A typical $L 3$ cavity spectrum is shown in Fig. 1(c). ${ }^{22}$ Here we will be concerned with the lowest order mode $M 1$. The spectrum of the $L 60$ cavity was obtained from the SNOM probe, positioned along the $L 60$, but close to the excitation spot. Its multimode spectrum in Fig. 1(d) consists of Fabry Perot modes of the closed section of the $W 1$ waveguide. The modes are non-equidistant due to the strong dispersion of the $W 1$ mode and not resolved in Fig. 1(d) near cut off, corresponding to the waveguide flat dispersion edge. The structure at shorter wavelength, which is also present in the $L 3$ spectrum ( $\sim M 4$ "), corresponds to a transverse resonance of the $W 1$ waveguide. Actually we will work only in the wavelength region between the $M 1$ and $M 2$ resonance of the $L 3$, so that we deal with a neat $L 60$ Fabry Perot spectrum, which derives completely from the even mode $W 1$ dispersion. The $L 60$ cavity volume is largely unpumped except at its end. Due to the presence of the QDs it is absorbing, which is, at least partially, responsible for the relatively broad resonance lines.

Fig. 2(a) shows the spectrum collected from the $L 3$ cavity location, in a spectral range around mode $M 1$ of the isolated cavity, separated from the $L 60$ by 4 barrier holes (see inset Fig. 1(a), for different excitation laser powers. No influence of the $L 60$ can be seen, and actually the complete spectrum is very similar to that of an isolated cavity (Fig. 1(c)). The absence of the $L 60$ spectra shows that in this configuration, we are not sensitive to the $L 60$ cavity, although this might also be pumped by the large pumping spot (estimated
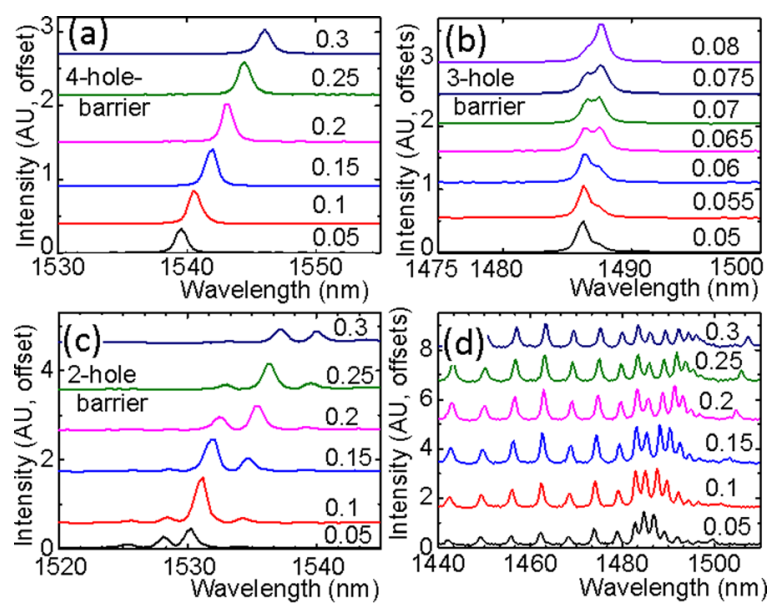

FIG. 2. (Color online) Laser tuned spectra. (a)-(c) Spectra of $L 3$ cavities, collected by the excitation objective, as coupled to an $L 60$ cavity by a 4-hole barrier (a), 3-hole barrier (b) and 2-hole barrier (c). For (a) and (c) the lattice constant $a=445 \mathrm{~nm}$; for (b), $a=425 \mathrm{~nm}$; all three cases: hole radius $r \approx 0.3 a$. The endholes radius of the $L 3$ cavities is $r^{\prime} \approx 0.22 a$; the endholes are not shifted. There are random and systematic fabrication variations in $r$ and $r^{\prime}$, responsible for (center) peak variations in (a) and (c). (d) $L 60$ cavity spectrum when coupled to an $L 3$ that has a resonance near $1490 \mathrm{~nm}$ ( $a=425 \mathrm{~nm}$, as in (b)); $r / a \approx 0.3$ ). The excitation laser spot was near the $L 3$ cavity, partially overlapping with the end of the $L 60$. The SNOM collection was near the other end of the $L 60$. The feature near $1500 \mathrm{~nm}$ that moves with the tuning is attributed to PL light from the $W 1$ waveguide cut off at the hot side, which scatters into the apertureless SNOM probe. The numbers at the curve give an approximate relative variation of the excitation laser power. $\sim 3 \mu \mathrm{m}$ in diameter). With increasing laser power, the peak is redshifted over a range which typically may correspond to more than two free spectral ranges (FSR) of the $L 60$ cavity (FSR $\sim 3 \mathrm{~nm}$ ). The tuning is due to the temperature increase of the semiconductor from the laser absorption and the temperature dependence of the refractive index. The heating is very local and decays within microns from the hot spot. It was verified that the tuning of the $L 60$ peaks under this condition was at least an order of magnitude less than the tuning of the $M 1$. The selective local heating was confirmed by a numerical calculation of the temperature profile using the geometry and thermal conductivities corresponding to the experiment. This selective photothermal tuning effect has been exploited before. ${ }^{4,10}$ The laser power was adjusted to obtain the required tuning in each experiment, as determined by the peak shifts. The maximum power delivered to the sample was estimated to be in the order of $10-100 \mu \mathrm{W}$. The power was not calibrated and may vary between experiments. The arbitrary units given for different data should not be intercompared. The signal is not proportional to the power since the PL intensity depends on power and because the QD efficiency decreases with temperature.

When the $L 3-L 60$ separation is reduced to a 3-hole barrier, the changes are still not large. However, when the $L 3$ is very finely tuned, a small, but clear peak splitting is observed in a narrow wavelength interval, as seen in Fig. 2(b). As will become clear from the following, this splitting is due to level anticrossing when the tuning power is such that the $L 3$ resonance would become degenerate with one of the $L 60$ cavity resonances.

As shown in Fig. 2(c), the spectrum as observed at the $L 3$ cavity site strikingly changes when it is separated from the $L 60$ by only a 2 -hole barrier (see inset Fig. 1(a)). A multiplet of three to four peaks is now observed, attributed to strong coupling with the $L 60$ resonances. Conversely, the $L 60$ resonances are also perturbed in the vicinity of the $L 3$ resonance wavelength, as seen in the $L 60$ spectrum of Fig. 2(d) (actually from another device than Fig. 2(c)). The spectrum was taken at the edge opposite to the position of the excitation spot, which partially explains why the spectrum near the long-wavelength cut-off is more smeared out than in Fig. 1(d). Note that the $L 60$ resonance positions are hardly affected by the tuning. Due to the closely spaced resonances, as well as due to the complication that the $L 60$ has one "hot end" with associated modified dispersion relation, we will not use the $L 60$ spectra for further analysis. It should be emphasized again that the $L 60$ spectrum is not visible in Fig. 2(c), other than by mixing up with the $L 3$ resonance. It confirms that we very locally probe the resonant mode intensity at the location of the $L 3$. Consequently, the resonances in Fig. 2(c) correspond to supermodes with appreciable intensities in both the short and long cavities.

To prove that the splitting in Fig. 2(c) is due to strong coupling, we have superimposed the $L 3$ spectra from another device for different detunings in Fig. 3(a). The prominent presence of deep minima in the superimposed spectra is a consequence of the avoided crossings of the $L 3$ resonances with the $L 60$ resonances. Another, more familiar way of showing the same effect is by plotting all peak positions of the $L 3$ resonances as a function of the tuning parameter, 

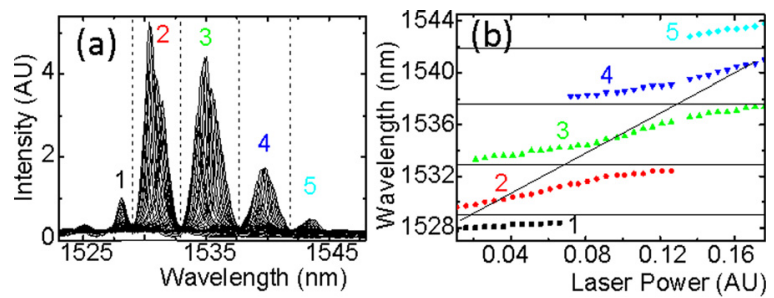

FIG. 3. (Color online) (a) Superimposed spectra of an $L 3$ cavity, as coupled to the $L 60$ cavity by a 2 -hole barrier when it is photothermally tuned (lattice parameter $a=445 \mathrm{~nm}$; hole radius $r \approx 0.3 a$; reduced hole radius $r^{\prime} \approx 0.22 a$ ) (b) Resonant peak positions of the $L 3$ cavity resonances of (a), as a function of excitation laser power. The thin solid lines are guides for the eye, but roughly correspond to the fixed $L 60$ resonances and tuned $L 3$ resonances for uncoupled cavities.

which in the present case is the laser power. This is done in Fig. 3(b). The resulting plot is a clear example of level anticrossing. The minima in Fig. 3(a) correspond to the horizontal lines in Fig. 3(b). When the resonances approach the minima in Fig. 3(a) or equivalently the horizontal lines in Fig. 3(b), they correspond to the unperturbed $L 60$ resonances, with intensities confined within the L60, and thus with vanishing intensity at the $L 3$ site.

To support the interpretation of the data, the $\mathrm{PhC}$ device was modeled as a set of coupled plane-parallel Fabry-Perot resonators, shown in Fig. 4(a). The two end mirrors $M_{1}$ and $M_{2}$ are assumed to have arbitrary large reflectivity. A partially transparent mirror $M_{3}$, inserted in between, simulates a coupled cavity system consisting of the $M_{1}-M_{3}$ and $M_{3}-M_{2}$ Fabry-Perot cavities. The resonances of this coupled system were determined by calculating the transmission spectrum of the system with the transfer matrices method. ${ }^{23}$ The spectra were calculated as a function of the coupling strength between the cavities, which is determined by the amplitude reflectivity $r_{3}$ of mirror $M_{3}$. Mirror $M_{3}$ was assumed to be lossless, implemented by taking $r_{3}{ }^{2}+t_{3}{ }^{2}=1$, where $t_{3}$ is the amplitude transmissivity of $M_{3}$. Both $t_{3}$ and $r_{3}$ were assumed to be real. To correspond to the experiments, the length $L_{2}$ of the $M_{3}-M_{2}$ cavity was taken as nearly $20 \times L_{1}$, where $L_{1}$ is the length of the $M_{1}-M_{3}$ cavity. The refractive index of the large cavity was assumed to be constant, $n_{\text {ave }}$, while the refractive index $n_{1}$ of the small cavity was varied around $n_{\text {ave }}$ to tune it over a few Free Spectral Ranges of the long cavity. The resulting frequencies of the coupled system are displayed in Fig. 4(b). The unperturbed frequencies of the long cavity are given by the horizontal lines, the unperturbed frequency of the short cavity by the sloped straight line. The value of $r_{3}$ was adjusted to qualitatively resemble the experi-
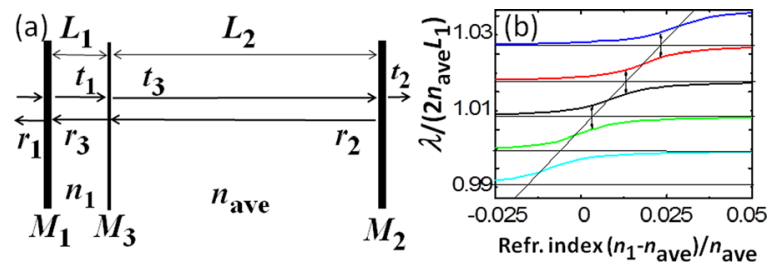

FIG. 4. (Color online) (a) Schematic of the coupled Fabry-Perot cavities. (b) Calculated positions of the transmission peaks of the coupled system of (a) as a function of the normalized refractive index $n_{1}$ of the small cavity. Normalized units $\lambda / 2 n_{\text {ave }} L_{1}$, where $n_{\text {ave }}$ is the average refactive index, assumed constant in the large cavity with length $L_{2}=20 L_{1}, r_{\mathrm{i}}, t_{\mathrm{i}}$ are the amplitude reflectivities and transmissivities of the mirrors $M_{\mathrm{i}}$. mental traces of Fig. 3(b), yielding a value of $r_{3} \sim 0.8$, or a power reflectivity of $\sim 0.6$.

The multiplet of peaks as displayed in Fig. 2(c), together with the pronounced level anticrossing behaviour displayed in Fig. 3(b), along with the confirmation of the interpretation of Fig. 4(b), convincingly proves the strong coupling between the cavities. The coupling strength is usually expressed as the frequency splitting at the anticrossing condition (vertical arrows in Fig. 4(b)). From Fig. 3(b), it follows that it is comparable to the mode separation of the large cavity. It is easily found from the Fabry-Perot model that this is the maximum splitting that can be obtained. From Fig. 3(b), it can be seen that the single level of the small cavity couples strongly to two levels of the large cavity simultaneously, meaning three peaks are seen simultaneously. The fourth simultaneously visible peak, meaning coupling to three modes, is just absent in Fig. 3, but was regularly observed in other data (e.g., Fig. 2(c)). The present observations are distinctly different from previous coupled cavity experiments that only involve one resonance per cavity, usually from photonic molecules build from identical cavities. Our experimental results should also be distinguished from the multiplet resonances that result from the coupling of a large number of identical cavities. ${ }^{3,9,24}$

In conclusion, we have experimentally demonstrated the simultaneous strong coupling of a single mode from a small $\mathrm{PhC}$ cavity with at least three modes of a large $\mathrm{PhC}$ cavity. The coupling was inferred from level anticrossing data by photothermal tuning of the small cavity over several resonance frequency intervals of the large cavity. Apart from any direct applications, the device is a convenient model system for studying the hybridization of states of coupled dissimilar objects.

The authors acknowledge E. J. Geluk, P. J. van Veldhoven, B. Smalbrugge, P. Nouwens, and T. de Vries for their help in the fabrication processes.

${ }^{1}$ H. Altug, D. Englund, and J. Vučković, Nat. Phys. 2, 484 (2006).

${ }^{2}$ D. O'Brien, M. D. Settle, T. Karle, and A. Michaeli, Opt. Express 15, 1228 (2007)

${ }^{3}$ M. Notomi, E. Kuramochi, and T. Tanabe, Nat. Photonics 2, 741 (2008).

${ }^{4}$ X. Yang, M. Yu, D.-L. Kwong, and C. W. Wong, Phys. Rev. Lett. 102, 173902 (2009).

${ }^{5}$ T. Gu, S. Kocaman, X. Yang, J. F. McMillan, M. B. Yu, G.-Q. Lo, D.-L. Kwong, and C. W. Wong, Appl. Phys. Lett. 98, 121103 (2011).

${ }^{6}$ S. Hughes, Phys. Rev. Lett. 98, 83603 (2007).

${ }^{7}$ H. Altug and J. Vucković, Opt. Express 13, 8819 (2005).

${ }^{8}$ A. Yariv, Y. Xu, R. K. Lee, and A. Scherer, Opt. Lett. 24, 711 (1999).

${ }^{9}$ J. Jágerská, N. Le Thomas, V. Zabelin, R. Houdré, W. Bogaerts, P. Dumon, and R. Baets, Opt. Lett. 34, 359-361 (2009).

${ }^{10}$ S. Kocaman, X. Yang, J. F. McMillan, M. B. Yu, D. L. Kwong, and C. W. Wong, Appl. Phys. Lett. 96, 221111 (2010).

${ }^{11}$ T. D. Happ, M. Kamp, A. Forchel, A. V. Bazhenov, I. I. Tartakovskii, A. Gorbunov, and V. D. Kulakovskii, J. Opt. Soc. Am. B 20, 373 (2003).

${ }^{12}$ K. A. Atlasov, K. F. Karlsson, A. Rudra, B. Dwir, and E. Kapon, Opt. Express 16, 16255 (2008).

${ }^{13}$ S. Vignolini, F. Intonti, M. Zani, F. Riboli, D. S. Wiersma, L. H. Li, L. Balet, M. Francardi, A. Gerardino, A. Fiore, and M. Gurioli, Appl. Phys. Lett. 94, 151103 (2009).

${ }^{14}$ S. Vignolini, F. Riboli, F. Intonti, D. S. Wiersma, L. Balet, L. H. Li, M. Francardi, A. Gerardino, A. Fiore, and M. Gurioli, Appl. Phys. Lett. 97, 063101 (2010).

${ }^{15}$ S. Vignolini, F. Riboli, D. S. Wiersma, L. Balet, L. H. Li, M. Francardi, A. Gerardino, A. Fiore, M. Gurioli, and F. Intonti, Appl. Phys. Lett. 96, 141114 (2010). 
${ }^{16}$ K. A. Atlasov, A. Rudra, B. Dwir, and E. Kapon, Opt. Express 19, 2619 (2011).

${ }^{17}$ A. R. A. Chalcraft, S. Lam, B. D. Jones, D. Szymanski, R. Oulton, A. C. T. Thijssen, M. S. Skolnick, D. M. Whittaker, T. F. Krauss, and A. M. Fox, Opt. Express 19, 5670 (2011).

${ }^{18}$ M. Brunstein, T. J. Karle, I. Sagnes, F. Raineri, J. Bloch, Y. Halioua, G. Beaudoin, L. Le Gratiet, J. A. Levenson, and A. M. Yacomotti, Appl. Phys. Lett. 99, 111101 (2011).

${ }^{19}$ C. J. M. Smith, R. M. De La Rue, M. Rattier, S. Olivier, H. Benisty, C. Weisbuch, T. F. Krauss, R. Houdré, and U. Oesterle, Appl. Phys. Lett. 78, 1487 (2001).
${ }^{20}$ J. Huang, S.-H. Kim, J. Gardner, P. Regreny, C. Seassal, P. A. Postigo, and A. Scherer, Appl. Phys. Lett. 99, 091110 (2011).

${ }^{21}$ A. Faraon, E. Waks, D. Englund, I. Fushman, and J. Vučković, Appl. Phys. Lett. 90, 073102 (2007).

${ }^{22}$ A. R. A. Chalcraft, S. Lam, D. O’Brien, T. F. Krauss, M. Sahin, D. Szymanski, D. Sanvitto, R. Oulton, M. S. Skolnick, A. M. Fox, D. M. Whittaker, H.-Y. Liu, and M. Hopkinson, Appl. Phys. Lett. 90, 241117 (2007).

${ }^{23}$ F. L. Pedrotti and L. S. Pedrotti, Introduction to Optics, (Englewood Cliffs, Prentice Hall International, 1993).

${ }^{24}$ A. Talneau, G. Aubin, A. Uddhammar, A. Berrier, M. Mulot, and S. Anand, Appl. Phys. Lett. 88, 201106 (2006). 